Thomas Allan, F.R.S., 1777-1833

Ox September 12, 1833, Thomas Allan, the Scottish mineralogist, died at the age of fifty-six years. Born in Edinburgh, he was educated at the High School and then entered his father's bank. On a visit to Paris, after the peace of Amions of 1802, he made the acquaintance of some French men of science and began collecting minerals. In 1808 , he published un alphabetical list of minerals in English, Fronch and German, and afterwards contributed papers to the Royal Socioty and the Royal Society of Edinburgh. His name is intimately associated with that of the romantic Sir Charles Giesecke (1761-1833) otherwise Karl Ludwig Metzler-“"a wanderer from Germany, learned in mineralogy, explorer, actor, journalist, Freemason, the friend of Mozart and of Schillor, and perhaps the original of William Meister". Giesecke, who had studied under Werner, had had a school of mineralogy at Copenhagen until the bombardment, and had then gone mineral collecting in Greenland. In 1811 he shipped a large collection of minerals to Denmark, but the ship being captured first by a French privateer and thon by a British frigate, was brought to Leith and the minerals were purchased by Allan for $£ 40$. Two years later, (Giesecke arrived in Hull with another collection and then learnt the fate of the first. Proceeding to Edinburgh, he was hospitably received and soon aftor was given the appointment of professor of mineralogy in the Royal Dublin Society. He died, in Dublin, a few months before Allan. In the study and improvement of his own collection Allan, for some years, was assisted by the Austrian geologist Wilhelm Haidinger (1795-1871) and it became the best in Scotland. After Allan's death it was sold and ultimately came into the possession of Robert Philip Grog (1826-1906), from whom it was purchasod in $\mathbf{1 8 6 0}$ for the Natural History Department of the British Museum.

\section{Research Exhibit at the Shipping Exhibition}

Ax the Shipping, Enginoering and Machinery Exhibition, which was opened at Olympia, London, on September 7, a comprehensive exhibit has been arranged by the Department of Scientific and Industrial Research to illustrate the work done by the Department itself and associated research bodies, to assist the 3ritish shipping and enginoering industries. The William Froude Laboratory and the Engineering and Metrology Departments of the National Physical Laboratory, and the Chemical Research Laboratory have oxhibits illustrating some of the investigations carried out at Teddington, while the Fuel Research Station, Creenwich, has one exhibit dealing with fires in bunkers and colliers, and another with pulverised fucl. The exhibit of the Chemical Research Luboratory illustrates tho important investigations, carried out in many parts of the world, on soa-water corrosion. Progress in the iron, steel and non-ferrous metals industries is largely due to the British Non-Ferrous Metals Research Association, the British Cast Iron Research Association and the Industrial Research Council of the National Federation of Iron and Steol Manufacturers, all of which have exhibits illustrating their many activities. Their exhibits range from the now lead alloys for electric cable sheathings and hoatresisting cast irons, to the coke for coko ovens and blast furnaces, and steol ingots. It is safe to say that there is no enginoering shop or shipbuilding yard in Groat Britain which does not benefit from tho researches illustrated at Olympia. The Exhibition will remain open until Septembor 23.

\section{The Expanding Universe}

WE have boon used to hearing strange things about the expanding universe. Prof. do Sitter contributes to the June issue of the Royal Astronomical Society's Monthly Notices an articlo which is largely of a nonmathomatical charactor and will throw light on tho subject for those of our readors who have been unable to follow tho elaborato discussions of the last few years on the subject: he advances the quasi-paradoxical viow that the stars are older than the universe. $Y_{t}$ is, he says, possible to adopt a point of view in which the "beginning of the universe" is no more remarkable a phenomenon than the passage of a comet through its porihelion. It is then possible to maintain a longer time scale for the individual starsas is demanded by theories of stellar evolution based on Eddington's mass luminosity relation-than is accordant with the interval which has olapsed since the galaxies started expanding, as judged by the observed recession of the spiral nebulæ. It must be borne in mind that tho expansion of the universe is the separation of galaxies, and leaves each galaxy unaltered, and that the galaxies can easily interpenetrate. 'The beginning of the universe, or minimum of one of the quantities connected with the universe, took place about ten thousand million years ago, but the stars aro much oldor. At this minimum the galaxies interpenetrated: and during this interpenetration the chance of stellar encounters was, of course, greater than it is now that our galaxy is left to itself. Modern theorios of the origin of the oarth suppose that our planotary system is the result of a close approach to the sun of some star. Now the evidence of the earth's crust points to an age of the earth of this order of magnitude, and it appoars conceivable that tho earth was formed at the "beginning of the universe" but that the sun was not, the "beginning" of the universe being simply a timo of minimum separation (indeed, interpenetration) of tho galaxies, the stars in which had already been in existence for some time.

\section{Progress in Facilities of Transport}

A Public lecture, entitled "Transport for a Century", was delivered by Sir Henry Fowler on September 5, in connexion with the Leicester myeting of the British Association. Probably no single item has played so great a part in the advance of civilisation during the past hundred years as the prozress in ease of transportation. The rapidity of actual transport of porsons and material has effected a very great change indeed in the lifo of people and 